\title{
Study of Sphenoid Sinus Anatomy in Relation to Endoscopic Surgery
}

\author{
Estudio Anatómico del Seno Esfenoidal en Relación con la Cirugía Endoscópica

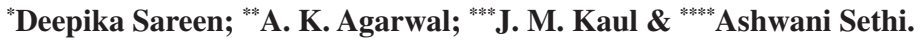

SAREEN, D.; AGARWAL, A. K.; KAUL, J. M. \& SETHI, A. Study of sphenoid sinus anatomy in relation to endoscopic surgery. Int. J. Morphol., 23(3):261-266, 2005.

SUMMARY: For radical surgery of the past, the precise definition of the clefts of the paranasal sinuses was of limited significance. In the recent years, the transsphenoidal approach to the pituitary gland has come into practice and the study of the surgical anatomy and relationships of the sphenoid sinus has gained increased significance. To better define this anatomy, 20 sphenoid sinuses in cadavers were dissected to reveal important anatomical relationships, dimensions, volume and pneumatization of the sphenoid sinus. The results of the study are discussed with particular reference to the important surgical anatomical features of the sphenoid sinus. The results also point towards the possibility of racial variations in terms of relationships of the sphenoid sinus to internal carotid artery and optic nerve in the Indian population.

KEY WORDS: Sphenoid sinus; Anatomy; Paranasal sinuses; Pituitary gland.

\section{INTRODUCTION}

The first description of sphenoid sinus mucocele in 1989 (Stankiewicz) has led to the development of a variety of surgical approaches to the sphenoid sinus eg. Intracranial, transeptal, transantral, external, etc. But all these approaches had their inherent problems. The endoscopic intranasal transsphenoidal approach, however, affords outstanding visualization and a safe, straightforward approach to the sphenoid sinus.

Inspite of the complex anatomy and important surgical relationships of the sphenoid sinus, a very few recent reports focus on it (Lang, 1989; Kennedy et al., 1990; Sethi et al,.1995 ; Elwany et al., 1983 and 1999). No such study has been reported from the Indian subcontinent. The aim of the present study is to describe the anatomy of the sphenoid sinus as it relates to transsphenoidal approach to hypophysis.

Sphenoid sinus is extremely variable in size, shape and relation to the sella. It is divided by one or more vertical septa that are often asymmetric.
The degree of pneumatization of the sphenoid sinus may vary considerably. The sphenoid sinus has been described as being postsellar, presellar or conchal. The postsellar type of sphenoid sinus is well pneumatized with bulging of the sellar floor into the sinus. The presellar type of sinus is situated in the anterior sphenoid bone and does not penetrate beyond the perpendicular plate of the tuberculum sellae. The conchal type of sphenoid sinus does not reach into the body of the sphenoid bone, and its anterior wall is separated from the sella turcica by approximately $10 \mathrm{~mm}$ of cancellous bone. In cases of extensive pneumatization, the maxillary nerve may bulge into the lateral wall of the sphenoid sinus. In extreme cases, the nerve may be entirely surrounded by pneumatization.

The ostia of the sphenoid sinus are usually located in the spheno ethmoidal recess, medial to the superior or supreme turbinate where they can usually be seen well with the endoscope.

The floor of sphenoid sinus is occasionally composed

* M. B. B. S. Junior resident, Department of ENT. M. A. M. C. and associated L. N. Hospital, New Delhi, India.

** M. S. Director Professor and Head of the Department, ENT. M. A. M. C. and associated L. N. Hospital, New Delhi, India.

${ }^{* * *}$ M. S. Professor and Head of the Department, Anatomy. M. A. M. C. and associated L. N. Hospital, New Delhi, India.

${ }^{* * * * *}$ M. S. Senior resident, Department of ENT. M. A. M. C. and associated L. N. Hospital, New Delhi, India.

Departments of ENT \& Head and Neck Surgery and Anatomy, Maulana Azad Medical College and associated L. N. Hospital, New Delhi, 110002, India. 
of ridges covering the vidian nerve. The medial and superior walls are usually smooth and the superior wall may balloon outwards from pressure of the sella turcica (hypophysis).

Two bulges on the lateral wall of the sinus are of considerable clinical significance. They are produced by the optic nerve and the internal carotid artery. Depending on the degree of pneumatization, these two bulges may be barely noticeable or very obvious.

\section{MATERIAL AND METHOD}

The material used consists of 20 cadaveric skulls. The skulls were dissected and sagittal sections observed for the anatomy and relationships of sphenoid sinus, pneumatization, interstitial septum and the level of sinus ostium.

\section{RESULTS}

Pneumatization (Graphic I, Fig. 1). The sphenoid sinuses were classified into presellar and postsellar types. The boundary between the two groups was defined by a verticalline running through tuberculum sellae. 15 sinuses $(75 \%)$ revealed a postsellar and 5 sinuses $(25 \%)$ revealed a presellar pneumatization.

Septation of sinuses (Graphic I, Figs. 2 and 3). 16 sinuses (80\%) had multiple septations and 4 sinuses (20\%) had a single septum.

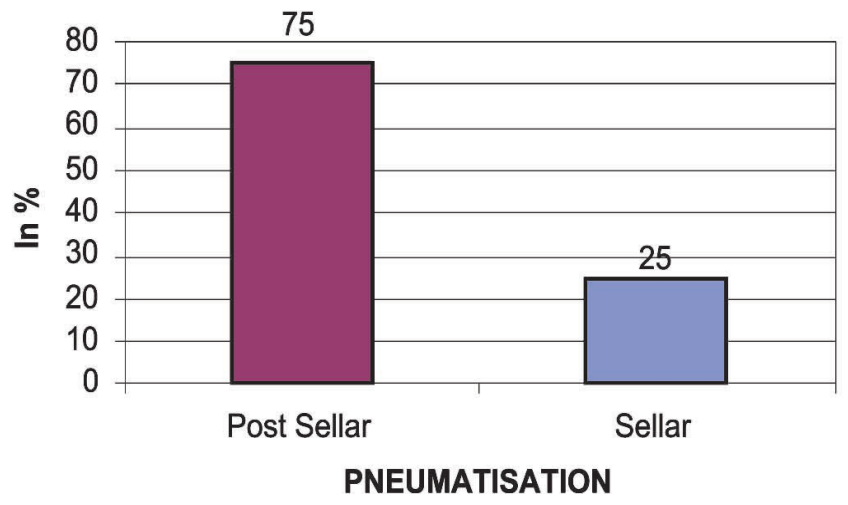

Dimensions of the sinuses (Graphic II). The anteroposterior diameter of the sinuses ranged from 1.3 to $3.4 \mathrm{~cm}$ (mean $=2.5$ $\mathrm{cm})$. Transverse diameter of the sinuses ranged from 1.2 to $5.0 \mathrm{~cm}($ mean $=2.8 \mathrm{~cm})$.

Vertical diameter of the sinuses. Ranged from 1.4 to $3.6 \mathrm{~cm}$ $($ mean $=2.2 \mathrm{~cm})$.

Volume of the sinuses. Ranged from 3.0 to $10.0 \mathrm{ml}$. (mean=5.8 $\mathrm{ml}$.)

Distance of sphenoid ostium (Graphic III). From midpoint on anterior wall of sphenoid sinus ranged from 0.1 to $0.4 \mathrm{~cm}$ (mean $=0.2 \mathrm{~cm}$ ). From the base of sphenoid ranged from 0.6 to $2.2 \mathrm{~cm}$ (mean $=1.6 \mathrm{~cm}$. From anterior end of superior turbinate ranged from 0.8 to $2.6 \mathrm{~cm}($ mean $=2.2 \mathrm{~cm})$.

Distance of anterior nasal spine to rostrum of sphenoid. Ranged from 7.2 to $9.3 \mathrm{~cm}$ (mean=7.9 cm)

\section{Relationships of the sphenoid sinus.}

-Internal carotid artery. Superolateral wall of one sinus (5\%) showed dehiscence due to the cavernous segment of the internal carotid artery.

-Optic nerve. Impression on the sinus wall due to optic nerve was not seen in any sinus in our study.

-Onodi cells. No onodi cells were identified.

-Floor of sella. No bulge or dehiscence was seen in the floor of sella.

-Maxillary nerve. None of the sinuses showed any bulge or dehiscence related to maxillary nerve.

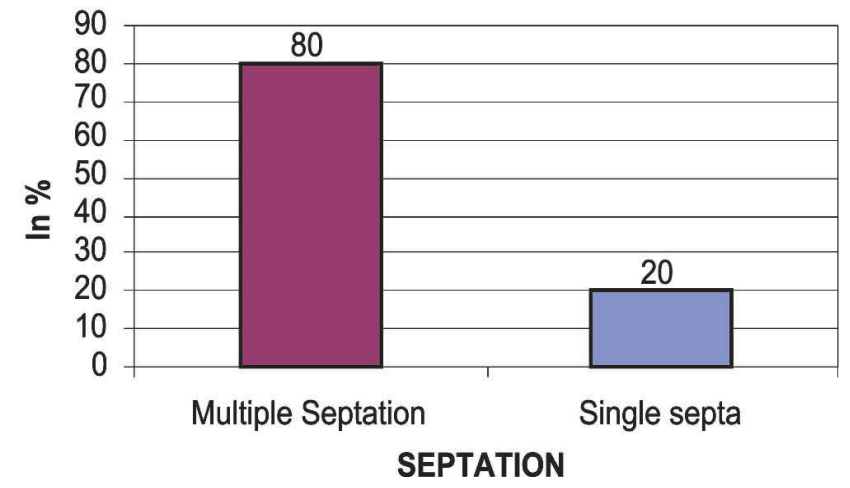

Graphic I. Pneumatization and septation of sphenoid sinus. 
Study of sphenoid sinus anatomy in relation to endoscopic surgery. Int. J. Morphol., 23(3):261-266, 2005.

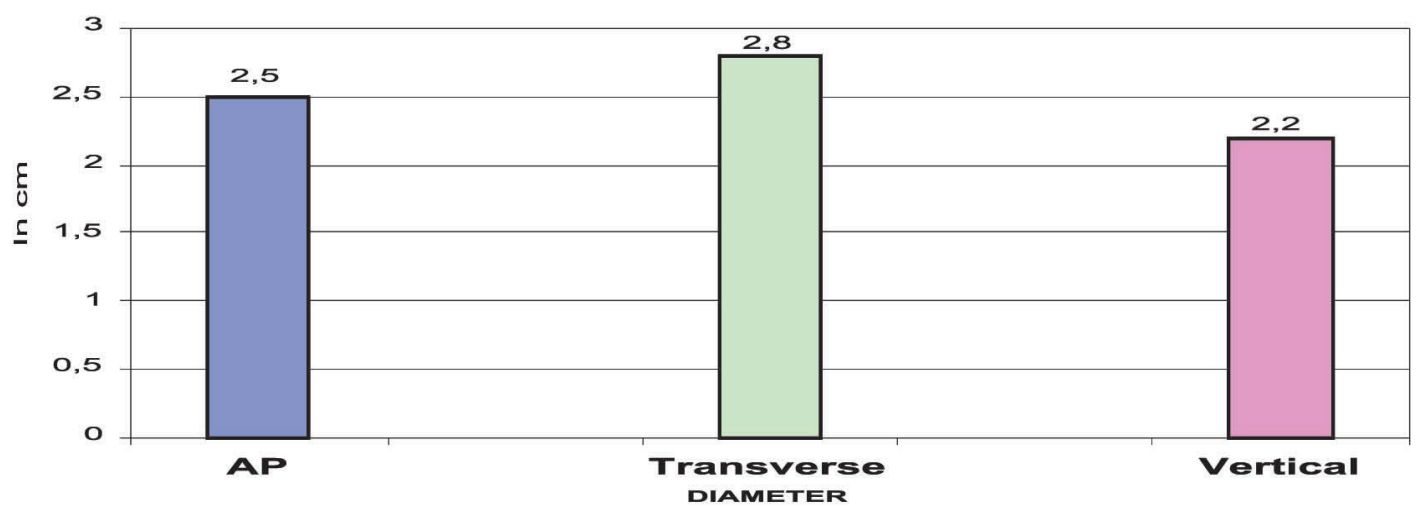

Graphic II. Mean AP, Transverse and Vertical diameters.

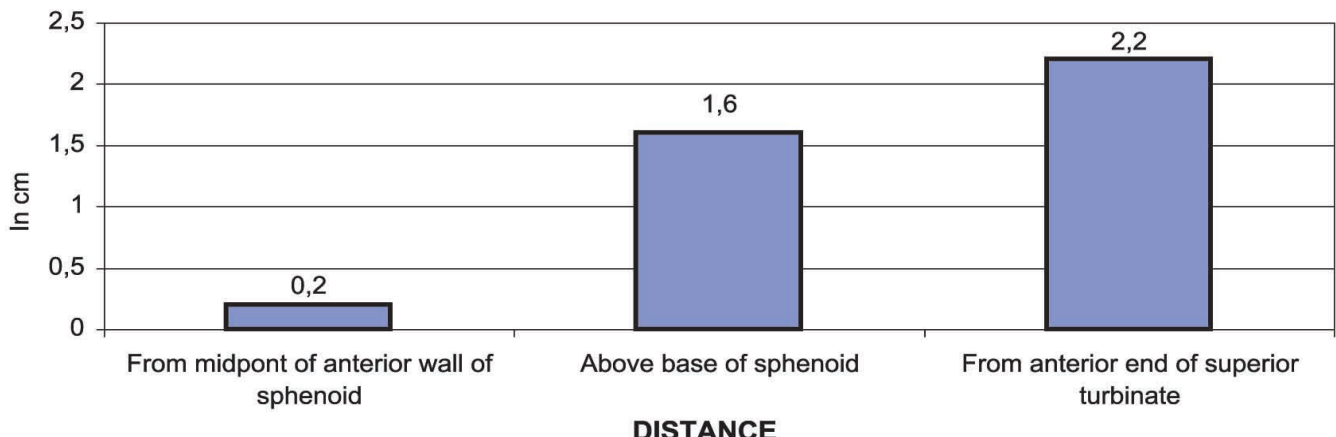

Graphic III. Distance of sphenoid ostium
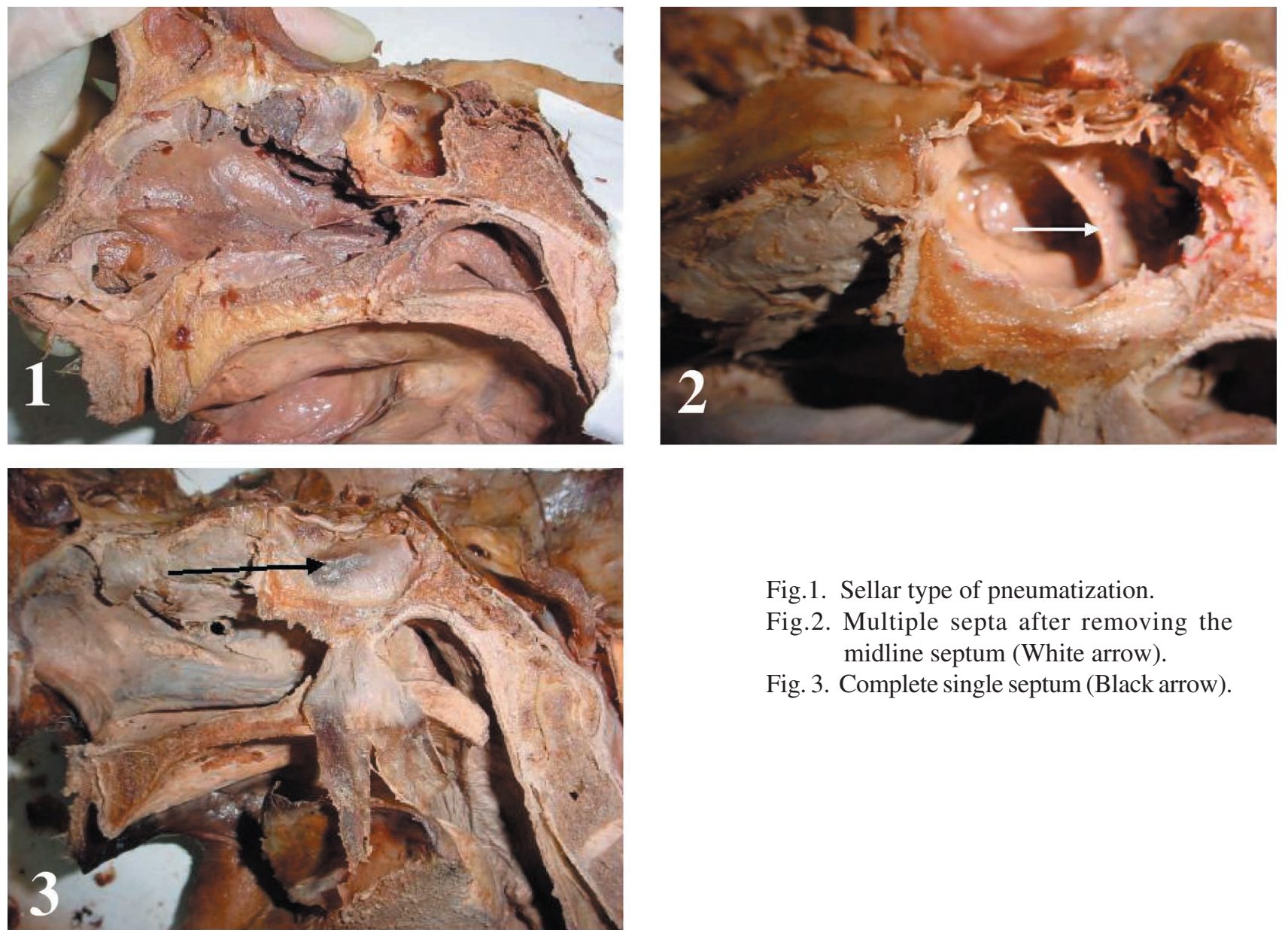

Fig.1. Sellar type of pneumatization.

Fig.2. Multiple septa after removing the midline septum (White arrow).

Fig. 3. Complete single septum (Black arrow). 


\section{DISCUSSION}

Throughout the history of medicine, numerous attempts have been made to illuminate and examine the inside of various cavities within the body. The paranasal sinuses alongwith their narrow passages, crevices, fissures and bony walls, place a particularly heavy demand on the design of instrumentation to be used for this purpose.

The endoscopic transnasal approach to sphenoid sinus is a technique, which has established itself in the recent years and demands a thorough knowledge of the surgical anatomy and a huge amount of anatomical variations involving the sphenoid sinus. In this study, the anatomy of the sphenoid sinus is studied from the viewpoint of an otolaryngologist, in an operative setting.

In our study, we identified two kinds of sphenoid pneumatization patterns, i.e., presellar (25\% of sinuses) and postsellar (75\% of sinuses). These results were similar to earlier works by Renn \& Rhoton (1975); Fuji et al. (1979); Elwany et al. (1983) and Sethi et al. Sinuses with postsellar pneumatization have been considered to be technically less demanding for a transsphenoidal hypophysectomy as compared to the presellar pneumatization.

Multiple intersinus septae were found in $80 \%$ of the sinuses in our study that is similar to an earlier study by Elwany et al. (1983) in which $73 \%$ sinuses had multiple septae. This signifies that the intersinal septum could not be used as a reliable guide to the midline during sinus surgery. The course of the septum is not necessarily median. It frequently deviates laterally and superiorly in its posterior course and inserts into the bony bulges over the optic nerve or the internal carotid artery. Awareness of this is particularly important if the septae in a sphenoid sinus are scheduled to be perforated or removed (Stammberger, 1991).

The average volume of the sinus in our study was 5.8 $\mathrm{ml}$. It has been estimated to be about 6 to $7.5 \mathrm{ml}$ (Ridpath, 1947; Simpson et al., 1967; Ballenger, 1977). In the series of Elwany et al. (1983) average size of presellar sinus was $2.5 \mathrm{ml}$. and it was $8.5 \mathrm{ml}$. for postsellar sinuses.

The average dimensions of the sinus were found to be: antero posterior- $2.5 \mathrm{~cm}$, transverse- $2.8 \mathrm{~cm}$ and vertical$2.2 \mathrm{~cm}$, in our study. The average dimensions in the study by Elwany et al. (1983) were found to be : antero posterior$3.1 \mathrm{~cm}$, transverse $-1.9 \mathrm{~cm}$ and vertical $-2.6 \mathrm{~cm}$.

The ostium of the sinus was found to be $0.2 \mathrm{~cm}$ from the midline, $1.6 \mathrm{~cm}$ above the floor of the sphenoid sinus and $2.2 \mathrm{~cm}$ from the anterior end of the superior turbinate on an average. Elwany et al. (1983) found the ostium at the level of 10 to $20 \mathrm{~mm}$ above the sinus floor. A pinhead ostium was reported in $13 \%$ sinuses by Lang and in 155 by Sethi et al.

The lateral wall of the sinus is hallmarked by indentations created by important structures, notably, the internal carotid artery and optic nerve. The internal carotid artery is the most medial structure in the cavernous sinus. We found dehiscence in the superolateral wall due to carotid artery in one sinus (5\%). Whereas Renn \& Rhoton reported bulges due to carotid artery in $71 \%$ of the sinuses and dehiscence in $4 \%$. Sethi et al. identified carotid bulges in $93 \%$ of the sinuses and Elwany et al. (1999) observed dehiscences in $4.8 \%$ of sinuses. This might indicate a racial variation in terms of relationship of the internal carotid artery to the sphenoid sinus, in the Indian population.

Impression of the optic nerve was not found in any sinus in our study. Sethi et al. noticed the bulge of optic nerve bilaterally in all their specimens. Elwany et al. (1999) found the bulge in $29 \%$ of their specimens. This might indicate a racial variation in terms of relationship of the optic nerve to the sphenoid sinus, in the Indian population.

During surgical procedures, the surgeon must always remember that the optic canal and the bulge of the internal carotid artery may only be covered by a very thin and occasionally fragmented bony layer in the area of the sphenoid and that these two vital structures may not be well protected (Stammberger).

Onodi cells are posterior ethmoid cells lying within the sphenoid bone. In the present series, no onodi cells were identified. However, Elwany et al. (1999) identified onodi cells in $7.5 \%$ of cases.

The most posterior point of an onodi cell of the posterior ethmoid may extend upto $1.5 \mathrm{~cm}$ beyond the most anterior point of the anterior wall of the sphenoid sinus. This is particularly important if the sphenoid sinus is to be opened endoscopically via the ethmoid. The anterior wall of the sphenoid sinus must never be sought behind the furthermost point of posterior ethmoid. This is the precise point where the risk of injury to the optic nerve is the greatest (Stammberger).

The roof of the sinus may vary in thickness and is hallmarked by the floor of sella. We did not see any dehiscence in the floor of sella. Likewise, no dehiscence was observed by Elwany et al. (1999). 
Maxillary nerve is related to the inferior part of the lateral wall of the sinus. None of the sinuses showed any bulge or dehiscences related to maxillary nerve. Sethi et al. recognized this bulge in $30 \%$ of the sinuses.

In cases of extensive pneumatization of the sphenoid sinus, the maxillary nerve may bulge into the lateral wall of the sinus or may be entirely surrounded by pneumatization and, thus, liable to iatrogenic injury.

Our study, however, differs significantly from the other studies in the past with respect to different relationships of the sphenoid sinus. Apart from the single sinus showing internal carotid artery dehiscence, no other bulge or dehiscence due to optic nerve, maxillary nerve or onodi cells were seen.

Endoscopic surgery of the sphenoid sinus can present the operator with a considerable challenge. Although the sphenoid sinus is a well-defined anatomic structure and many recommendations have been made regarding the surgical approaches, little has been written about the endoscopic approach that uses a discrete, easily identifiable and reliable anatomic landmark.

Caliberated instruments are often recommended to gauge sphenoid location based on the average distance of sinus from the anterior nasal spine. In our study, this distance was found to be $7.9 \mathrm{~cm}$ on an average.

It is seen that the superior turbinate is a consistent and reliable anatomic marker for localizing the sphenoid sinus (Bolger et al., 1999). It may prove useful in all endoscopic surgeries involving the sphenoid sinus, but especially so in cases with distorted anatomy, which is often seen in revision surgeries because of resection of middle turbinates. The superior turbinate, however, is rarely resected and is often available as an anatomical landmark to help guide the surgeon. In our study, the average distance from the anterior end of the superior turbinate to the sinus ostium was $2.2 \mathrm{~cm}$.

\section{CONCLUSIONS}

From the study, the following points of surgical significance may be concluded:

1. Pneumatization of the sphenoid sinus is highly variable and may be a helpful guide in deciding the surgical approach to the hypophysis.

2. Patterns of septation in the sphenoid sinus are highly variable making it an unreliable guide to the midline. Moreover, the septae may be attached to the bony bulges over the optic nerve or the internal carotid artery, which has to be taken into account if the septae are scheduled to be perforated.

3. The surgeon must always remember that the optic canal and internal carotid artery may not be well protected in the area of sphenoid and are liable to injury.

4. The superior turbinate is a reliable and consistent anatomic marker for localization of the sphenoid sinus, especially, in revision surgeries where middle turbinate has been already removed.

5. The study suggests strong possibilities of racial variations in terms of relationship of the internal carotid artery and optic nerve to the sphenoid sinus, in the Indian population.

SAREEN, D.; AGARWAL, A. K.; KAUL, J. M. \& SETHI, A. Estudio anatómico del seno esfenoidal en relación con la cirugía endoscópica. Int. J. Morphol., 23(3):261-266, 2005.

RESUMEN: En las cirugías radicales del pasado, la definición precisa de las hendiduras de los senos paranasales fueron de importancia limitada. En los últimos años, el abordaje transesfenoidal de la hipófisis y las relaciones del seno esfenoidal han tenido en la práctica y en el estudio de la anatomía quirúrgica, un significativo incremento. Para definir mejor esta anatomía, 20 senos esfenoidales fueron disecados en cadáveres para revelar importantes relaciones anatómicas, dimensiones, volumen y neumatización del seno esfenoidal. Los resultados de este estudio son discutidos con referencia particular para la anatomía quirúrgica del seno esfenoidal. Los resultados también apuntan hacia la posibilidad de variaciones raciales, en términos de relaciones del seno esfenoidal con la arteria carótida interna y el nervio óptico, en la población de la India.

PALABRAS CLAVE: Seno esfenoidal; Anatomía; Senos paranasales; Hipófisis. 


\section{REFERENCES}

Bolger, W. E.; Keyes, A. S. \& Lanza, D. C. Use of the superior meatus and superior turbinate in the endoscopic approach to the sphenoid sinus. Otolaryngol. Head. Neck. Surg., 120(3):308-13, 1999.

Ballenger, J. J. In: Diseases of the Nose, Throat and Ear. 12. ed. Lea and Febiger, Philadelphia, 1977. p 8.

Elwany, S.; Yacout, Y. M.; Talaat, M.; El-Nahass, M.; Grunied, A. \& Talaat, M. Surgical anatomy of sphenoid sinus. J. Laryngol. Otol., 97:227-41, 1983.

Elwany, S.; Elsaeid, I. \& Thabet, H. Endoscopic anatomy of sphenoid sinus. J. Laryngol. Otol., 113:122-6, 1999.

Fuji, K.; Chambers, A. \& Rhoton, J. Neurosurgical relationships of the sphenoid sinus: A microsurgical study. J. Neurosurg., 50:31-9, 1979.

Kennedy, D.; Zinrich, H. \& Hassab, M. The internal carotid artery as it relates to endoscopic spheno-ethmoidectomy. Am J Rhinol., 4:7-12, 1990.

Lang, J. Clinical anatomy of the Nose, Nasal cavity and Paranasal Sinuses. Thieme Medical Publishers. Inc. New York. 1989. pp 85-98.

Renn, W. H. \& Rhoton, A. L. Microsurgical anatomy of the sellar region. The J. Neurosurg., 43:288-98, 1975.

Ridpath, F. R. In: Disease of the Nose, Throat and Ear. Third ed., W. B. Saunders Company, Philadelphia, 1947. p 57.

Sethi, D. S.; Stanley, R. E. \& Pillay, P. K. Endoscopic anatomy of sphenoid sinus and sella turcica. J. Laryngol. Otol., 109:951-5, 1995.

Simpson, J. F.; Robin, I. G.; Ballantyne, J. C. \& Groves, J. In: Synopsis of Otolaryngology. 2. ed. John Wright and Sons Ltd., Bristol. 1967. p 148.

Stammberger, H. \& Kopp, W. In: Functional Endoscopic Sinus Surgery: The Messerklinger Technique. 1991. pp 67-8, 210.

Stankiewicz, J. A. The endoscopic approach to the sphenoid sinus. Laryngoscope, 99:218-22, 1989.
Correspondence to:

Dr. Deepika Sareen

$\mathcal{E}-80$, Naraina Vifar

$\mathcal{N e w}$ Delfi

$I \mathcal{N}(\mathcal{D} I \mathcal{A}$

Phone №: 91-11-55399725

Email-dr_sethi@rediffmail.com

Received : 23-05-2005

Accepted: 02-08-2005 